\title{
Retrospective Analysis of Etiology, Incidence and Management of Facial Trauma Over 5 Years in North India: A Clinical Audit
}

\author{
${ }^{1}$ Rohit Sharma, ${ }^{2}$ Vandana Esht, ${ }^{3}$ Pallvi Goomer
}

\section{ABSTRACT}

Aim: To analyze etiology, incidence and management of facial trauma over a period of 5 years in a tertiary care center in North India.

Materials and methods: Records of 195 patients with 274 facial fractures were analyzed retrospectively from 2009 to 2013. Fractures were classified according to anatomical area involved (zygoma, maxilla, mandible, teeth), and etiology was divided into road traffic accidents (RTAs), falls, sports injuries and assaults. It was found that RTA was most common etiologic factor for facial trauma, followed by falls, assaults and sports injuries. Mandibular fractures were most common, followed by midface fractures and dental injuries. Various treatment options were also evaluated.

Results: Mandibular fractures were more common than midface fractures. Most common line of treatment was open reduction and internal fixation with mini-plate fixation. Mandible reconstruction was done in one case of bone defect following a gun-shot injury. Coronoidectomy had to be performed in one case of zygoma fracture.

Conclusion: Patient's best interest, affordability and general well being should be kept in mind while managing trauma of maxillofacial region. Surgeon should utilize his knowledge to the best possible level as any injury to this region has a direct impact on psyche as well as general well being of patient.

Keywords: Clinical audit, Oral and maxillofacial surgery, Facial trauma.

How to cite this article: Sharma R, Esht V, Goomer P. Retrospective Analysis of Etiology, Incidence and Management of Facial Trauma Over 5 Years in North India: A Clinical Audit. J Postgrad Med Edu Res 2015;49(2):59-61.

Source of support: Nil

Conflict of interest: None

${ }^{1,3}$ Senior Lecturer, ${ }^{2}$ Assistant Professor

1 Department of Oral and Maxillofacial Surgery, Yamuna Institute of Dental Sciences and Research, Yamuna Nagar Haryana, India

${ }^{2}$ Department of Sports Physiotherapy, MM Institute of Physiotherapy and Rehabilitation, Ambala, Haryana, India

${ }^{3}$ Department of Pedodontics, BRS Dental College and Hospital Panchkula, Haryana, India

Corresponding Author: Rohit Sharma, Senior Lecturer Department of Oral and Maxillofacial Surgery, Yamuna Institute of Dental Sciences and Research, Yamuna Nagar, Haryana India, Phone: 09915607043, e-mail: dr.rohitsharma@yahoo.com

\section{INTRODUCTION}

The injuries to the maxillofacial region are of significance as this region gives protection to the cranial cavity and its contents from the front, and also as this region is associated with appearance, and other vital functions, such as eating, hearing, seeing, smelling and tasting, having a direct impact on the person's quality of life. ${ }^{1}$

The first analysis of facial injuries was done in $1962 .{ }^{2} \mathrm{~A}$ number of studies have been done since then examining the epidemiology of facial fractures. ${ }^{3-5}$

The present study examines the records of 195 patients with facial fractures in a tertiary care center in North India, from 2009 to 2013, reviewing the mechanism of injury, age and sex of the patient, the type of injury and the treatment provided.

\section{MATERIALS AND METHODS}

The records of 195 patients with 274 facial injuries in a tertiary care center in North India, from 2009 to 2013 were reviewed. The history, clinical examination, radiographic examination, diagnosis and treatment were confirmed through the records.

The parameters evaluated, based on the records, are as under:

- Age of the patient

- Sex of the patient

- Etiology of trauma

- Anatomical area involved

- Treatment.

\section{RESULTS}

Majority of the subjects in this study were found to be males, with male to female ratio being about 6:1 (167 males, 28 females), which is in between those reported by various studies (2:1 to 9:1). ${ }^{1,6}$ Males are more prone to trauma due to their outdoor activities, aggressive driving and alcoholism ${ }^{6}$ (Table 1).

The youngest patient was 1-year-old, whereas the oldest was aged 86 years (average age 31.6 years). The most commonly involved age group was 20 to 40 years ( 99 patients, $50.77 \%$ ), followed by 40 to 60 years (44 patients, $22.56 \%$ ) (Table 2). 
Road traffic accident (RTA) was the most common etiological factor, accounting for 154 injuries (78.97\%), followed by falls (27 injuries, $13.85 \%$ ), which is in accordance with Adeyemo et $\mathrm{al}^{7}$ (Table 3).

One hundred and ninety-one patients $(77.44 \%)$ reported within first 3 days of injury, whereas the rest $(22.56 \%)$ reported more than 3 days after the trauma (Table 4).

Sixty-eight patients $(34.87 \%)$ had more than one type of facial fracture, with mandibular fractures (155 fractures, $56.57 \%$ ) being more common than the midface fractures (114 fractures, 41.61\%) (Table 5).

The most common sites for mandibular fractures were parasymphysis ( 46 fractures, $29.68 \%$ ) and condyle (45 fractures, $39.03 \%$ ), followed by angle (28 fractures, $18.06 \%$ ), body ( 24 fractures $14.48 \%$ ), symphysis (6 fractures $3.87 \%$ ), dentoalveolar (3 fractures, $1.94 \%$ ), ramus (2 fractures, $1.29 \%$ ) and coronoid (1 fracture, $0.65 \%$ ) (Table 6). Zygomatic fracture (66 fractures, $29.68 \%$ ) was the most common midface fracture, followed by maxilla fractures (20 fractures, $13.89 \%$ ) LeFort II fractures (10 fractures, 6.94\%), LeFort I fractures ( 9 fractures, $6.25 \%$ ), dentoalveolar (8 fractures, $5.55 \%$ ) and LeFort III fractures (1 fracture, $0.69 \%$ ) (Table 7 ).

Among the dental injuries, three patients had avulsed teeth, one patient had tooth intrusion and one had tooth fracture (Ellis class III).

Regarding the treatment modalities used, open reduction was done in majority of the cases and fixation was done using miniplates (106 cases, $54.36 \%$ ). Transosseous wiring was done in 2 cases (1.03\%). Sixty cases (30.77\%) were treated through closed reduction using arch bars, and 21 patients $(10.77 \%)$ required no active intervention as the fractures were undisplaced. In one case, mandible was reconstructed using a reconstruction plate as there was bone defect present following a gun-shot injury. Coronoidectomy had to be performed in one case of zygoma fracture as the patient reported with a malunited zygomatic fracture 3 months after the injury as was having difficulty in mouth opening as the coronoid process was impinging upon the depressed zygomatic bone. In patients with avulsed teeth, splinting of the teeth back into their original position was done. The patient with fractured tooth underwent root canal treatment for the affected tooth (Table 8).

\section{DISCUSSION}

The present study analyses the patients with injuries to the maxillofacial region, from the years 2009 to 2013. It was seen that road traffic accidents (RTAs) were the most common etiological factor of maxillofacial trauma, followed by falls. This is in accordance with various studies in India as well as other countries. ${ }^{1,8,9}$ Fractures of
Table 1: Gender

\begin{tabular}{lll}
\hline Gender & Number & Percentage \\
\hline Male & 167 & 85.64 \\
Female & 28 & 14.36 \\
\hline Total & 195 & 100 \\
\hline
\end{tabular}

Table 2: Age groups

\begin{tabular}{lll}
\hline Age groups & Number & Percentage \\
\hline Less than 20 & 38 & 19.49 \\
$20-40$ & 99 & 50.77 \\
$40-60$ & 44 & 22.56 \\
More than 60 & 14 & 7.18 \\
\hline Total & 195 & 100 \\
\hline
\end{tabular}

Table 3: Etiology

\begin{tabular}{lll}
\hline Factor & Number & Percentage \\
\hline RTA & 154 & 78.97 \\
Fall & 27 & 13.85 \\
Assault & 7 & 3.59 \\
Sports injury & 7 & 3.59 \\
\hline Total & 195 & 100 \\
\hline
\end{tabular}

Table 4: Time of reporting

\begin{tabular}{lll}
\hline Time & Number & Percentage \\
\hline Within 3 days & 151 & 77.44 \\
After 3 days & 44 & 22.56 \\
\hline Total & 195 & 100 \\
\hline
\end{tabular}

Table 5: Different injury sites

\begin{tabular}{lll}
\hline Bones & Number & Percentage \\
\hline Mandible & 155 & 56.57 \\
Maxilla & 28 & 10.22 \\
Zygoma & 66 & 24.09 \\
LeFort I & 09 & 3.28 \\
LeFort II & 10 & 3.65 \\
LeFort III & 01 & 0.37 \\
Dental injuries & 05 & 1.82 \\
\hline Total & 274 & 100 \\
\hline
\end{tabular}

Table 6: Mandible fracture sites

\begin{tabular}{lll}
\hline Fracture & Number & Percentage \\
\hline Parasymphysis & 46 & 29.68 \\
Condyle & 45 & 29.03 \\
Angle & 28 & 18.06 \\
Body & 24 & 15.48 \\
Midsymphysis & 06 & 3.87 \\
Ramus & 02 & 1.29 \\
Coronoid & 01 & 0.65 \\
Dentoalveolar & 03 & 1.94 \\
\hline Total & 155 & 100 \\
\hline
\end{tabular}

the mandible were more commonly observed, a finding consistent with Singh et al, ${ }^{1}$ which may be due to the fact that the mandible is a more prominent bone than the strongly supported bones of the middle third of the face.

Regarding the treatment modalities used, open reduction and internal fixation was the most commonly used 


\begin{tabular}{lll}
\hline \multicolumn{3}{c}{ Table 7: Midface injury sites } \\
\hline Fracture & Number & Percentage \\
\hline Zygoma & 66 & 57.89 \\
Maxilla & 20 & 17.54 \\
LeFort I & 09 & 7.89 \\
LeFort II & 10 & 8.78 \\
LeFort III & 01 & 0.88 \\
Dentoalveolar & 08 & 7.02 \\
\hline Total & 114 & 100 \\
\hline
\end{tabular}

Table 8: Treatment modalities

\begin{tabular}{lll}
\hline Treatment & Number & Percentage \\
\hline Open reduction and plate fixation & 106 & 54.36 \\
Transosseous wiring & 2 & 1.03 \\
Closed reduction & 60 & 30.77 \\
Conservative management & 22 & 11.28 \\
Reconstruction & 01 & 0.51 \\
Splinting & 03 & 1.54 \\
Coronoidectomy & 01 & 0.51 \\
\hline Total & 195 & 100 \\
\hline
\end{tabular}

modality, and it has been proven to be the most effective method for treating mandibular fractures (Ajmal et al). ${ }^{10}$ However, according to Danda et al, no significant clinical difference exists between patients undergoing closed reduction and open reduction with internal fixation. ${ }^{11}$

Minimally, displaced fractures can be managed conservatively or by closed reduction, as described by Singh et al. ${ }^{1}$ The cases with extensive displacement have to be treated with open reduction. ${ }^{12}$ However, patients with underlying neurological deficit, spinal injuries or medically compromised patients can be managed conservatively, keeping in mind the patient's well being. In epileptic patients, intermaxillary fixation for the management of fractures cannot be done.

\section{CONCLUSION}

The present study describes the etiology, incidence, time of reporting, area involved and the treatment imparted to maxillofacial trauma patients. The patient's best interest, affordability and general well-being should

be kept in mind while managing maxillofacial trauma. In handling trauma patients, the maxillofacial surgeon should utilize his knowledge to the best possible level as any injury to this region has a direct impact on the psyche as well as the general well-being of the patient.

\section{REFERENCES}

1. Singh V, Malkunje L, Mohammad S, et al. The maxillofacial injuries: a study. Natl J Maxillofac Surg 2012;3(2):166-171.

2. McCoy FJ, Chandler RA, Magnan CG, et al. An analysis of facial fractures and their complications. Plast Reconstr Surg 1962;29(4):381-391.

3. Scherer M, Sullivan WG, Smith DJ Jr, et al. An analysis of 1423 facial fractures in 788 patients at an urban trauma center. J Trauma 1989;29(3):388-390.

4. Brook IM, Wood N. Aetiology and incidence of facial fractures in adults. Int J Oral Surg 1983;12(5):293-298.

5. Bagheri SC, Dierks EJ, Kademani D, et al. Application of a facial injury severity scale in craniomaxillofacial trauma. J Oral Maxillofac Surg 2006;64(3):408-414.

6. Gassner R, Tuli T, Hachl O, et al. Craniomaxillofacial trauma: a 10 years review of 9,543 cases with 21,067 injuries. J Craniomaxillofac Surg 2003;31(1):51-61.

7. Adeyemo WI, Ladeinde AL, Ogunlewe MO, et al. Trends and characteristics of oral and maxillofacial injuries in Nigeria: a review of the literature. Head Face Med 2005;1(1):7.

8. Al Ahmed HE, Jaber MA, Abu Fanas SH, et al. The pattern of maxillofacial fractures in Sharjah, United Arab Emirates: a review of 230 cases. Oral Surg Oral Med Oral Pathol Endod 2004;98(2):166-170.

9. Malara P, Malara B, Drugacz J. Characteristics of maxillofacial injuries resulting from road traffic accidents: a 5 years review from the case records from department of maxillofacial surgery in Katowice, Poland. Head Face Med 2006;2(8):27.

10. Ajmal S, Khan MA, Jadoon $H$, et al. Management protocol of mandibular fractures at Pakistan Institute of Medical Sciences, Islamabad, Pakistan. J Ayub Med Coll Abbottabad 2007;19(3):51-55.

11. Danda AK, Muthusekhar MR, Narayanan V, et al. Open versus closed treatment of unilateral subcondylar and condylar neck fractures: a prospective randomized clinical study. J Oral Maxillofac Surg 2010;68(6):1238-1241.

12. Back CP, McLean NR, Anderson PJ, et al. The conservative management of facial fractures: indications and outcomes. J Plast Reconstr Aesthet Surg 2007;60(2):146-151. 